\title{
UMA CAPITAL E O GÊNERO PANEGÍRICO'
}

\author{
UNA CAPITAL Y EL GÉNERO PANEGÍRICO
}

\section{A CAPITAL LETTER AND THE PANEGYRIC GENRE}

DOI: $10.22481 /$ rbba.v10i01.8818

Marcello Moreira Universidade Estadual do Sudoeste da Bahia, Bahia, Brasil. ID Lattes: http://lattes.cnpq.br/4062269068371059

ORCID: https://orcid.org/0000-0001-6827-2772

Endereço eletrônico: moreira.marcello@gmail.com

Raeltom Santos Munizo Universidade Estadual do Sudoeste da Bahia, Bahia, Brasil. ID Lattes: http://lattes.cnpq.br/6581946481136697 Endereço Eletrônico: munizo_raeltom@ hotmail.com

\section{RESUMO}

O presente trabalho tem por fito analisar a letra capital do poema "Panegírico ao Marquês de Marialva", atribuído ao poeta luso-brasileiro Manuel Botelho de Oliveira. A leitura de tal letra versal maiúscula será levada a termo tendo em vista a sua disposição no processo de demarcação e organização de gêneros de poemas no interior do livro Música do Parnasso, no qual estão reunidos diversos tipos de textos poéticos e retóricos atribuídos ao artificie, a exemplo de sonetos, redondinhas, madrigais, romances, canções e décimas. Analisar-se-á o assunto ilustrado em tal aparato visual-textual em seu caráter particular do panegírico, para, posteriormente, tentarmos relacionar o tipo de cena desenhada com as noções sobre um distinto costume de se pensar o gênero panegírico, em certas sociedades de outrora. 
Palavras-Chave: Letra capital; Panegírico; Retórica; Poética.

\section{RESUMEN}

Este trabajo tiene como objetivo analizar la letra capital del poema "Panegírico ao Marquês de Marialva", atribuido al poeta portugués-brasileño Manuel Botelho de Oliveira. La lectura de dicha letra capital se realizará en vista de su disposición en el proceso de demarcación y organización de géneros de poemas dentro del libro Música do Parnasso, en el que se atribuyen al poeta varios tipos de textos poéticos y retóricos, como sonetos, rondas, madrigales, romances, canciones y décimas. El tema ilustrado en este aparato visual-textual será analizado en su carácter particular del panegírico, para luego intentar relacionar el tipo de escena dibujada con las nociones sobre uno costumbre distinto de pensar el género panegírico, en determinadas sociedades de antaño.

Palabras Clave: Letra capital; Panegírico; Retórica; Poética.

\section{ABSTRACT}

This paper aims at analysing the capital letter inserted in the poem entitled "panegyric to the Marquis of Marialva", attributed to the Luso-Brazilian poet Manuel Botelho de Oliveira. In the analysis of the referred capital letter it will be considered its position in the book Música do Parnasso, in which several types of poetic and rhetorical texts are attributed to the artifice, such as sonnets, rounds, madrigals, romances, songs and tenths. This letter is a mark textual that indicates the beginning of a new book section - that of the poems composed in octave rhyme. It will be considered also how this particular capital letter relates itself to the panegyric, amplifying its sense.

Keywords: Capital letter; Panagyric; Rhetoric; Poetics.

\section{INTROITO}

\section{O "PANEGYRICO/ AO/ EXCELLENTISSIMO SENHOR/ MARQUEZ DE}

MARIALVA;/ Conde de Cantanhede, no tem-/ po que governava as Armas de Portugal" é um discurso impresso na compilação de poemas também atribuídos ao fidalgo e poeta lusobrasileiro Manoel Botelho de Oliveira, intitulada MUSICA/DO/ PARNASSO/DIVIDIDAS EM 
QUATRO COROS/ DE RIMAS/ PORTUGUESAS, CASTELHA-/ nas, Italianas, \& Latinas./ COM SEU DESCANTE COMICO REDUSI-/ do em duas Comédias,/ OFFERECIDA/ AO EXCELLENTISSIMO SENHOR DOM NUNO/ Alvares Pereyra de Mello, Duque do Cadaval, \&c./ E ENTOADA/ PELO CAPITAM MOR MANOEL BOTELHO/ de Oliveyra, Fidalgo da Caza de Sua/ Magestade./ LISBOA.// Na Officina de MIGUEL MANESCAL, Impressor do Santo Officio, Anno de 1705. Tal poema panegirical em louvor ao Marquês de Marialva está disposto, nesse livro, na seção "VERSOS/ VARIOS QUE/ PERTENCEM/ AO PRIMEYRO/ CORO/ DAS RIMAS/ PORTUGUESAS.// ESCRITTOS/ A VARIOS ASSUMPTOS". A estrofe de tal panegírico é a oitava rima heroica, com versos decassílabos, de esquema de rimas ABABABCC; a maioria de suas estrofes é margeada lateralmente por brevíssimas notas chamadas escólios e sua estância primeira apresenta uma bela letra capital, sobre a qual apresentaremos algumas considerações neste estudo.

O Marquês de Marialva, em questão, é Dom Antônio Luis de Menezes, o III Conde da vila de Cantanhede, que foi um nobre varão português, de cuja data de nascimento não se tem conhecimento, porém, seu falecimento ocorreu no "[...] anno de 1675, a 16 de Agosto, como diz o Padre Santa Maria, no Anno Historico, e Souza, nas Memor. Histor. e Geneologic. dos Grandes de Portugal [...]" (ANÔNIMO, [entre 1806 e 1817], p. 6). É famoso por sua atuação nas mais significativas batalhas da Guerra da Restauração, ocorrida entre Portugal e Espanha, no século XVII, e que resultou na independência de Portugal do Reino de Castela. Dom Antônio Luís de Menezes é celebrado como um dos principais heróis ou generais dessa guerra, em virtude dos grandes feitos realizados em batalhas, os quais lhe renderam vários discursos panegiricais comemorativos dessas ações ou mesmo de sua vida.

O panegírico é uma espécie de discurso laudatório instituído pela tratadística retórica cuja finalidade é estabelecer a amplificação da vida e virtudes de caracteres agentes que obraram importantes feitos em prol do bem comum da nação. O panegírico pertence ao gênero epidítico ou demonstrativo, o qual é definido por Aristóteles, na Retórica (2005), como parte da técnica retórica que visa ao louvor ou vitupério de coisas virtuosas ou viciosas, belas ou vergonhosas. A prática retórica e poética de produzir panegíricos estava alinhada à política de manutenção da ordem social, uma vez que tal gênero discursivo estabelecia a exemplificação de ações e virtudes dignas de serem imitadas pelo distinto público que, em tempos de outrora, os recepcionava decorosamente. Destarte, o panegirico, conquanto seja discurso inventado em 
relação com os preceitos da instituição retórica, estava fundado naquele princípio ajuizado por Aristóteles, na Poética (1973), de que a poesia deve deleitar à medida que doutrina o público.

\section{SOBRE A LETRA CAPITAL}

O lexicógrafo e membro da Ordem dos Clérigos Regulares, Raphael Bluteau (16381734), em seu Vocabulário português e latino, áulico, anatômico, arquitetônico..., publicado entre os anos de 1712 e 1728, em Coimbra, pela imprensa do Colégio das Artes da Companhia de Jesus, define a capital ou cabídula como letra maiúscula com que se começa um capítulo, parágrafo ou seção textual. Em muitos livros impressos seiscentistas pode-se averiguar o uso da letra capital no início de seus prólogos aos leitores, em dedicatórias, na carta ou parecer da Santa Inquisição, ou em início de seções textuais que constituem uma divisão e/ou subdivisão da disposição dos gêneros textuais no interior do livro. A capital, ao ser inscrita, por exemplo, no primeiro texto de uma seção do livro constituída por sonetos de matéria amatória, acaba também corroborando para com a demarcação da divisão ou subdivisão das seções textuais no interior dessa "obra". Em Música do Parnasso, o uso das capitais nos reforça esse argumento. Ademais, em impressos dos anos Seiscentos e Setecentos, esse tipo de letra versal comumente vem inscrita dentro de uma forma quadrada, adornada com motivos florais, da fauna, bíblicos, amatórios, et cetera, bem como apresenta dimensões amplas em comparação ao tamanho das letras capitulares de livros do século XXI, por exemplo.

O "Panegírico ao Marquês de Marialva", atribuído a Manuel Botelho de Oliveira, está disposto na compilação de poemas Música do Parnasso, em sua segunda parte da seção ou coro de poemas escritos em língua portuguesa. Esse discurso panegírico estruturado ou disposto em oitavas vem após os poemas do gênero "soneto" e inicia uma seção de apenas dois poemas escritos em oitavas. O segundo poema em oitava rima dessa seção é o conhecidíssimo "A rosa". Isso foi posto para apresentarmos também as circunstâncias da disposição das letras capitais nesse coro de rimas escritos em "lingoage" portuguesa acerca de vários assuntos. Como dito, o panegírico em louvor da vida e virtudes do Marquês da vila lusitana Marialva inicia uma seção de poemas em oitavas, por isso, ele apresenta uma capital, já que é de conhecimento corrente que a capital inicia, por exemplo, seções ou capítulos textuais. Já o poema “A rosa”, que sucede ao "Panegírico ao Marquês de Marialva" na seção com textos em oitava rima, não apresenta uma capital, justamente em razão de sua disposição posterior. Ademais, na seção de sonetos 
pertencente à parte de versos escritos em língua portuguesa acerca de vários assuntos, somente o primeiro soneto intitulado "A MORTE FELICISSIMA/ DE HUM JAVALI PELO/ tiro que nelle fez hu[m]a Infanta/ de Portugal" apresenta uma inicial com motivos florais. Do mesmo modo, podemos averiguar a presença da letra versal somente no primeiro poema do gênero Canção, o qual constitui a terceira seção da tipologia do coro de rimas ora apresentado. $\mathrm{Na}$ seção seguinte às Canções, tem-se o poema “A ILHA/ DE MARE' TERMO DESTA/ Cidade da Bahia.”, o qual é um único poema pertencente ao gênero Silva e, por isso, recebeu a capital "I", que forma e adorna o verbo "Ias" com figuras florais. Na segunda parte ou seção de temas variados escritos em língua portuguesa, tem-se a última letra capitular situada no poema primevo da subseção Romances. Deste modo, podemos constatar que a disposição das capitais na segunda parte do coro de rimas em língua portuguesa sobre vários assuntos se dá apenas em poemas que iniciam uma espécie de subseção constituída por poema(s) ordenado(s) por uma tipologia de texto, como sonetos, oitavas, canções, silva e romances. Assim sendo, as letras capitais são unidades textuais que coparticipam da demarcação ou organização interna das seções poemáticas que constituem a "obra" Música do Parnasso.

É digno de nota que somente a capital do "Panegírico ao Marquês de Marialva" apresenta um quadro ornamental constituído por motivos religiosos e não figuras florais como as outras capitais que fazem parte daquela seção ou coro de vários tipos de poemas, os quais foram escritos em língua portuguesa e que balizam sobre diversos assuntos.

Em Música do Parnasso, temos somente outra letra capital, além daquela do panegírico, que é adornada por motivos bíblicos. Essa letra capitular está inscrita na Canção I intitulada "SOLICITA A ANARDA PARA/ hum campo", a qual está disposta no "SEGUNDO/ CORO/ DAS/ RIMAS/ CASTELHANAS// EM VERSOS AMOROSOS/ da mesma Anarda.”. Tal capitular é a letra "V" e constitui a palavra "Ven", e o quadro no qual está inscrita essa versal apresenta figuras ou motivos bíblicos que ilustram uma cena de um homem com uma ovelha sob os ombros indo ao encontro de algumas pessoas, as quais estão em um ambiente campestre. Além disso, na parte inferior do quadro da capitular ornada com aquela cena tem-se a inscrição "LVC. XV", a qual interpretamos como referência ao livro bíblico de Lucas, Capítulo 15. A cena ilustrada nos é referida logo no início de tal perícope do livro de Lucas, e versa sobre a parábola do guardador de rebanhos e da ovelha desgarrada, doutrina esta contada por Jesus a fim de responder à disseminada murmuração de muitos fariseus e escribas sobre a proximidade Dele com pecadores. Urge trazer à baila que a história referenciada na ilustração e a inscrição 
do quadro capitular mantém uma relação com a matéria da canção a Anarda, relação essa que se pensa logo quando da leitura do título ou didascália que encima a Canção.

\section{A VERSAL DO "PANEGÍRICO AO MARQUÊS DE MARILAVA" E NOÇÕES SOBRE A PRÁTICA PANEGIRICAL}

Conquanto seja uma unidade textual constituinte do "Panegírico ao Marquês de Marialva", compilado no impresso Música do Parnasso, a letra versal de tal discurso permitenos, por ora, estabelecer uma leitura, de certa forma, independente do tipo de poema que ela constitui. Muitas gravuras que ilustram textos antigos apresentam um sentido que pode ser depreendido a partir de outro tipo de recepção visual, sem necessariamente precisar ler os textos que as acompanham. De modo símile, Márcio Ricardo Coelho Muniz (2007, p. 3), ao estudar uma ilustrada tradução francesa de uma anônima Ars Moriendi de fins do dito medievo, argumenta-nos que as gravuras dispostas ao lado do texto pressupõem uma análise visual e particular do assunto que o texto também partilha. Posto isso, segue a estrofe primeira do "Panegírico ao Marquês de Marialva" com a letra capital que a constitui, com o fito de estabelecermos determinadas considerações acerca de tal unidade textual versal:

Figura 1: Capital do "Panegírico ao Marquês de Marialva".

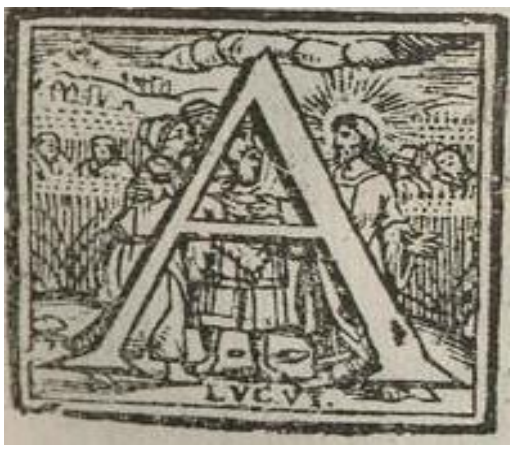

GORA, Aquilles Lusitano, agora, Se tanto concedeis se aspiro a tanto, Deponde hum pouco a lança vencedora, Inclinay vossa fronte ao rude canto: Se minha vea vossa fama adora, Corra em Mavorcio, corra em sabio espãto, Chea de gloria, de Hippocrene chea, No Mundo a fama no discurso a vea.

Fonte: Música do Parnasso, de Manuel Botelho de Oliveira (1705, página 91).

No quadro anterior, no qual se inscreve a capital " $A$ " da palavra "AGORA", observamos, no plano atrás da letra versal, uma gravura que ilustra um ajuntamento de pessoas em uma área ao ar livre e com algumas distantes casas e morros atrás delas. Nesse quadro, há um recuado ajuntamento de pessoas que, pelo que podemos inferir dos seus gestos e direção 
dos rostos, estão observando atentamente certos personagens dispostos a sua frente, os quais nos são enfatizados, no quadro da capitular, pela posição central e mais ampliada de sua imagem. Um desses personagens centralizados e enfatizados no ornado quadro da letra capital é figurado com uma auréola na cabeça, com o cabelo comprido e com uma espécie de túnica, de um modo que, por meio de tais elementos e características, podemos inferir que se trata da típica imagem europeia de Jesus Cristo. Ademais, essa figura, que se supõe ser Cristo, está estendendo a mão para algumas pessoas que estão em sua frente e o observam atentamente, como se elas estivessem ouvindo-O discursar. Por outro lado, na parte inferior e central de tal quadro da capitular, está inscrito: "LVC. VI.", abreviatura que se pode interpretar como referência do Livro Bíblico de Lucas, Capítulo 6., capítulo este que se refere à escolha dos dozes apóstolos que Jesus elegeu dentre seus discípulos, e também nos apresenta o sermão das bem-aventuranças, o qual foi o discurso inaugural da pregação realizada por Jesus, em uma planície, para a multidão e os doze apóstolos que o seguiam. Em tal sermão da planície, Jesus Cristo traz exemplos de virtudes fundamentais para exortar aqueles ouvintes a imitá-los ou segui-los, para que possam alcançar o Reino de Deus. Nesse livro, demonstra-se uma das principais circunstâncias por meio da qual Jesus pregava a Doutrina, a saber, através da prática de discursar para uma multidão, dentre a qual, algumas vezes, Ele usava determinados tipos de pessoas como exemplo para se ensinar ao ajuntamento que testemunhava suas palavras. Vejase abaixo, o versículo 17 do Capítulo 6 do Livro de Lucas, que exemplifica tal circunstância de pregação que podemos inferir a partir da inscrição e das imagens que ornam a letra capitular:

Desceu [Jesus] da montanha com eles [os doze apóstolos], e parou num lugar plano, onde havia numeroso grupo de discípulos e imensa multidão de pessoas de toda a Judeia, de Jerusalém e do litoral do Tiro e Sidônia. Tinham vindo para ouvi-lo e ser curados de suas doenças. Os atormentados por espíritos impuros também eram curados. E toda a multidão procurava tocá-lo, porque dele saía uma força que a todos curava (BÍBLIA DE JERUSALÉM, Lucas, 6 , 17-19).

Esse excerto do livro de Lucas, que melhor se relaciona com a imagem da capital, portanto, remete-nos à ensinança de distintos tipos de ouvintes efetuada por Jesus, que extraía membro(s) do ajuntamento para tomá-lo(s) como exemplo, curá-los de suas tormentas e enfermidades, a fim de também ensinar aos ouvintes sobre as virtudes e atos fundamentais para o bem viver, assim como repreender os vícios constatados. 
A história que a inscrição abreviada do livro de Lucas e a cena de um ajuntamento de pessoas desenhada no quadro da capital referenciam nos faz pensar também no costume de publicação e recepção de discursos panegíricos em sociedades antigas. Não estamos aqui asseverando que tal quadro capitular foi produzido com o fito de significar a prática de demonstração de panegíricos em público, pois isso seria uma hipótese brumosa. Estamos argumentando que a cena ilustrada no quadro da versal do "Panegírico ao Marquês de Marialva", de algum modo, nos faz pensar no modo como se ajuizava as circunstâncias para ser demonstrado ou pronunciado o panegírico em períodos antigos. Nos séculos XVI, XVII e XVIII, é lugar comum apresentar em tratados de retórica que tratam do gênero panegirical que tal tipo de discurso, na Grécia antiga, era uma prática laudatória pronunciada durante determinados festejos pan-helênicos, nos quais se ajuntavam povos de várias poleis com vistas a assistirem e competirem em jogos, como os Olímpicos, bem como resolverem demandas políticas e negociarem comércios entre as cidades-estado etc. Por exemplo, em seu tratado sobre os elementos de retórica, o presbítero da Congregação do Oratório de Lisboa, Antônio Pereira (1759, p. 27), assim aborda tal tipo de oração laudatória: "Panegyrico vem do nome Grego Panegyris, que significa ajuntamento, ou concurso de toda a naçaõ. Porque em certos dias de grande celebridade he que os Gregos celebravaõ os seus Heroes”. De modo similar, outro tratado de eloquência e arte retórica do período argumenta que:

Panegyrico era huma Oraçaõ, em que os Antigos empenhavaõ o maior apparato da sua eloquencia: Costumava dizer se nos seus jogos solemnes, e na prezença de toda a multidão, que a eles concorria: Os primeiros louvores se dirigiaõ ao Nume, que presidia á solemnidade: seguiaõ-se os da Cidade, aonde os jogos se celebravaõ, dahi os do [...] Magistrado, que se achava prezente; e ao depois os dos Athletas, que levavaõ os premios (MELLO, 1766, p. 250).

Destarte, a noção de panegírico na sociedade grega, portanto, concerne a festividades de caráter político e público que congregavam todo (pan) povo (gyrikos) em uma reunião ou assembleia, na qual o que estava em voga é a concórdia e a comemoração da reunião dos povos. Ademais, à medida mesma em que tais tipos de discursos celebravam tais ajuntamentos, eles também doutrinavam o público, apresentando-lhe valores e exemplos fundamentais para a manutenção da ordem ou bons costumes das poleis. Esses ajuntamentos eram o momento de ouvir e aprender.

Em Roma, a prática de pronunciar panegírico em público era mais restrita, uma vez que o ambiente de demonstração era o senado romano, onde normalmente as pessoas condecoradas, 
pelo imperador, com o cargo político de cônsul produziam panegíricos como espécie de voto de agradecimento à mercê concedida. Exemplo disso é o "Panegírico ao Imperador Trajano", do cônsul Plínio, o Jovem, que, conforme (ROCHE, 2011, p. 1), foi pronunciado por Plínio em primeiro de setembro, do ano $100 \mathrm{~d}$. C, ao imperador Trajano, aquando de uma reunião no senado, na qual Plínio, o jovem, agradeceu ao imperador pela obtenção do consulado. Entendese o panegírico na antiga Roma como uma prática gratulatória e laudatória pronunciada aquando da reunião ou assembleia de um grupo político seleto. Tal tipo de voto de agradecimento apresentava um forte caráter político, pois pinta as virtudes e ações que constituem um modelo de Optimus princeps, bem como apresenta valores fundamentais à ordem social.

Portanto, o significado de panegirico entre os povos antigos estava associado à prática de demonstrar discursos laudatórios e doutrinários em determinadas reuniões ou "ajuntamento" dos povos. Acerca desse costume, João de Barros nos fala no excerto abaixo, o qual é parte do exórdio de seu Panegírico do Rei Dom Joao III que, conforme Manuel Rodrigues Lapa (1937), foi composto em 1533, e pronunciado nesse período, pelo próprio artíficie ao monarca, em presença da corte e de outros habitantes da cidade de Évora, durante a ocasião em que se festejava a restauração de um aqueduto nessa cidade:

Não sem causa, muito alto e muito poderoso Rei e Senhor, costumavam nos tempos antigos louvar os excelentes homens em sua presença, porque dando louvor justo e manifesto ao grande merecimento das pessoas, assi os presentes, como os que viessem depois, tomassem exemplo e fizessem tais obras, com que merecessem o mesmo louvor; e pera o nome dos tais ser mais celebrado, soíam nas mores festas e ajuntamentos do povo publicar os tais louvores, que por esta razão chamavam "panegírico", que quer dizer "ajuntamento". (BARROS, 1943, p. 1).

Nos séculos XVI e XVII, contudo, essa prática laudatória se adequa em outro telos que, por sua vez, atende aos interesses da política católica como, por exemplo, doutrinar a população para que se estabeleça uma ordem social enraizada nos dogmas do catolicismo.

O panegírico, nos Estados ibéricos, é uma certa "arte de viver", em sua lógica ou telos católico e contrarreformista, que ele objetiva figurar efetuando-a como ordo, tornando uma posição ocupada no espaço social uma posição "objetiva", frente a outras posições, e, simultaneamente, eletiva, porque realizada nesta arte da vida como voluntas ou vontade de ser e fazer, nobreza como nascimento e ao mesmo tempo como ação (MOREIRA, 2011, p. 187). 
A prática de produzir panegíricos nos anos seiscentistas e setecentistas, portanto, adequou-se aos costumes e valores doutrinados pela política desses períodos. Da mesma forma, os motivos bíblicos ilustrados em quadros capitulares do século XVII e XVIII, de grosso modo, sofrem influências de valores catolicistas constituintes da sociedade de antão.

\section{CONSIDERAÇÕES FINAIS}

A letra versal "A" da palavra "Agora" que inicia a estrofe primeira do discurso panegírico ao Marquês de Marialva, atribuído a Manuel Botelho de Oliveira, é uma unidade textual que possui um sentido a partir da análise particular da cena que constitui a imagem, assim como possui um sentido interpretado por meio de sua relação com o tipo de poema que ela ornamenta e também é um dispositivo paratextual que participa da organização ou disposição do panegírico no interior do livro.

A capital de tal discurso retórico-poético é ornada com uma cena de cunho bíblico que remete à prática de doutrina coletiva exercitada por Jesus Cristo. Essa leitura da cena ilustrada foi possível também pela presença da inscrição situada na parte inferior do quadro da letra versal que faz referência ao sermão da planície, do Livro Bíblico de Lucas.

A letra versal também é um dispositivo paratextual que organiza e demarca a seção textual do gênero Oitava rima, na qual está contida o poema "Panegírico ao Marquês de Marialva", uma vez que as capitais do livro Música do Parnasso são responsáveis por dá início e dividir as seções textuais dos vários gêneros poéticos do livro.

$\mathrm{O}$ motivo bíblico que a letra cabídula figura nos remete também à antiga prática dos povos gregos e romanos de se pronunciar panegíricos em ajuntamentos festivos e em assembleias políticas, onde se doutrinava o público ouvinte, apresentando-lhe os vícios e aquelas virtudes ajuizadas fundamentais para a manutenção do bem comum.

\section{REFERÊNCIAS}

ANÔNIMO. D. Antonio Luiz de Menezes, III Conde de Cantanhede, I. Marquez de Marialva. - [Lisboa: Philopatrica, entre 1806 e 1817] ([Lisboa: Na Officina de Simão Thaddeo Ferreira]). - 1 gravura: buril e ponteado, p\&b ; 16,7x11,1 cm (matriz). 
Aristóteles. Poética. Tradução, comentários e índices analítico e onomástico de Eudoro de Souza. In: Os Pensadores: Aristóteles. São Paulo: Abril Cultural, 1973. — (Os Pensadores; v. IV).

Retórica. Introdução de Manuel Alexandre Júnior. Tradução e notas de Manuel Alexandre Júnior; Paulo Farmhouse Alberto; Abel do Nascimento Pena. Lisboa: Imprensa Nacional-Casa da Moeda, 2005.

BARROS, João de. Panegíricos. Texto restituído, prefácio e notas de M. Rodrigues Lapa. Lisboa: Livraria Sá da Costa, 1937.

BÍBLIA DE JERUSALÉM. Nova edição, revista e ampliada. $8^{a}$ impressão. São Paulo: Paulus, 2012.

BLUTEAU, Raphael. Vocabulario portuguez \& latino: aulico, anatomico, architectonico ... Coimbra: Collegio das Artes da Companhia de Jesu, 1712 - 1728. 8 v.

MELlO, F. de P. de S. e de. THEATRO DA ElOQUENCIA,/ OU ARTE DE RHETORICA,/ FUNDADA NOS PRECEITOS DOS/ melhores Oradores Gregos, e Latinos.// Lisboa:/ na officina de FRANCISCO BORGES DE SOUSA./ Anno de MDCCLXVI.

MOREIRA, M. O louvor ao Marquês de Marialva: um estudo sobre o panegírico. In: REVISTA USP, São Paulo, n.88, p. 183-192, dezembro/fevereiro 2010-2011.

MUNIZ, M. R. C. Sobre a Arte de Morrer no Outono Medieval. Outros Tempos, v.4, n.4, UEMA, pp. 01-15, 2007.

OLIVEIRA, Manuel Botelho de. Música do Parnasso dividida em quatro coros de rimas portuguesas, castelhanas, italianas \& latinas / pelo Capitam Mor Manoel Botelho de Oliveyra, Fidalgo da Caza de Sua Majestade. - Lisboa: na Officina de Miguel Manescal, impressor do Santo Ofício, 1705.

PEREIRA, A. Elementos da Invençam ou Locuçam Retorica, ou Principios da Eloquencia... Lisboa, na Officina Patriarcal de Francisco Luiz Ameno, 1759.

ROCHE, P. - Pliny's thanksgiving: an introduction to the Panegyricus $\|$. In: ROCHE, P. (org.). Pliny's praise: the Panegyricus in the roman world. Cambridge: Cambridge University Press, 2011, p. 1-28.

\section{NOTAS}

\footnotetext{
${ }^{\text {i }}$ Este estudo se estabelece a partir de uma pesquisa acadêmica em nível de mestrado desenvolvida por nós no Programa de Pós-Graduação da Universidade Estadual do Sudoeste da Bahia, cujo título da dissertação é "Encômio e memória em panegíricos ao Marquês de Marialva".
} 